\section{The Human Use of Animals: Case Studies in Ethical Choice}

\author{
F B Orlans, T L Beauchamp, $R$ \\ Dresser, D B Morton, J P Gluck, \\ New York and Oxford, Oxford Uni- \\ versity Press, 1998 , xi +330 pages, \\ $£ 39.59$ (hc) $£ 20.00$ (sc).
}

This is an extremely valuable book for anyone concerned, practically or theoretically, with the ethics of the human use (or abuse) of animals in a variety of ways. The authors are respectively two philosophers, one lawyer, one veterinarian and one psychologist, based mainly at American universities.

The book opens with a chapter explaining the main types of ethical theory as distinguished by philosophers and how they have been applied to the issue of the moral status of animals. The main distinction here is between utilitarian theories and rights-based theories (in this case animal rights). Perhaps more subdivisions would have been useful without making the book too forbidding; for example, different types of utilitarianism might have been usefully contrasted (for example, for their different implications for killing animals as opposed to hurting them).

The remaining sixteen chapters examine a range of controversies over representative but particular (mostly American, but of general significance) disputed cases relating to: (A) biomedical research or purposes (illustrated by reference to baboon-human liver transplants in Pittsburgh, head injury experiments on primates at the University of Pennsylvania, the Harvard Oncomouse and its patenting); (B) cosmetic testing; (C) behavioural research (illustrated by reference to Washoe and her successor, animal aggression studies by Elwood and Ostermeyer at Queen's University,
Belfast, Harlow and his monkeys without mothers); (D) wild-life research (illustrated by a disputed killing of a rareish wild bird for a museum collection); (E) compulsory dissection etc in life science courses (illustrated by the fifteen-year-old Californian Jennifer Graham's refusal to dissect a frog); (F) food animals (force-feeding of geese, veal crates, broiler chickens); (G) companion animals (docking of dogs' tails, sale by pounds in some American cities of lost or stray dogs or cats to laboratories), and as a final surprise, $(\mathrm{H})$ animal sacrifice (by adherents of the Santeria religion in Florida). There is also a chapter on the public's right to know, illustrated by disputes over this between the Progressive Animal Welfare Society (PAWS) and the University of Washington and its Animal Care Committee.

Thus most of the central ethical issues (the use of animals in biomedical research, cosmetic safety testing, behavioural research, wild-life research, education) are covered by way of these representative examples, the exceptions I have noted being circuses and field sports.

After a very helpful and full factual account of each case, both what was done and what lawful efforts (and how successful they were), have been made to stop its being done, the main ethical attitudes which can be adopted, both for and against such use of animals, are presented well and impartially and related to the distinctions made in the first chapter.

This book would be an excellent basis for a course on the moral status of animals whether for life science or philosophy students, and should be of interest to all those concerned to work out their views on this subject, with reference to concrete issues.

T L S SPRIGGE

University of Edinburgh $\begin{array}{ll}\text { The New Dictionary } & \text { ơf } \\ \text { Medical Ethics on } & \text { or } \\ \text { Edited by Kenneth M Boyd, Roger } & \text { on }\end{array}$

Higgs and Anthony J Pinching, Lon? don, BMJ Publishing Group, 1997, 285 pages, $£ 19.95$.

The Dictionary of Medical Ethics puto lished in 1977 and revised and enlarged in 1981 was one of the pioneer ing achievements wrought in th United Kingdom by a cluster of concerned clinicians, philosopheps and theologians led by Edward Sho ter. The New Dictionary of Medial Ethics is its dynastic successor, n⿳巛口⿲丿⿺乚一匕 edited by three worthy heirs to $A \mathbb{Q}$ Duncan, $G R$ Dunstan and $R \mathbf{B}$ Welbourn. Satisfied users of the pre? ous volume will rejoice that the size and format remain much the same does the number of contributors and that the "same spirit of interdiscipnary cooperation and concern for the practicalities of medical ethics" eydures. The orientation toward affairss in the United Kingdom is still o feature. So what is novel apart from second generation of editors and $\cos$ tributors?

The editors claim to have effecte different approach, better able to cover the enormous increase in public ano professional interest in medical ethics and to keep up with recent massive shifts in the culture of health care? Their main purpose is now to "clari and question rather than to definese Topics have been revised or replace and diversity has been deliberatefy sought by encouraging the 150 or so well chosen contributors to give $\overline{6}$ personal flavour to their pieces". TiR more than 700 entries range fro short essays to brief definitions. Inev? tably there will be disagreement abou selection of topics, allocation of spage and the degree to which diversity of style and meaning is beneficial. Mos. readers whether searching, seeking $\theta$ merely browsing will find easy access 